\title{
Risky Shifts And The Model Of Communicative Events
}

\author{
Maha El Shinnawy, (Email: mshinnawy@aucegypt.edu), American University in Cairo, Egypt \\ Ajay Vinze, Arizona State University \\ Amr Mortagy, American University in Cairo, Egypt
}

\begin{abstract}
Group interaction frequently results in group members changing their prior beliefs to a more extreme position. This is referred to as group polarization. Using the model of communicative events, this paper proposes that task, medium of communication, group composition and their interaction will have an effect on the phenomenon of group polarization. A laboratory experiment was conducted to address these questions. A $2 \times 2 \times 2$ factorial design was used to analyze the results. The analysis indicates that polarization does in fact occur and that the level of polarization varies depending on: the medium of communication, the task characteristics and their interaction. The composition of the group does not have a significant effect on polarization. The findings reported in this study have significance for developers, users and researchers of collaborative systems and for social-psychologists who study the phenomenon of group enhanced attitude shifts.
\end{abstract}

\section{INTRODUCTION}

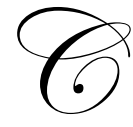

ollaborative systems are concerned with enhancing the quality of group communication (Koch 2005) using group technology. The impact of these systems on both the outcomes from group discussion and its effect on the process of communication is coming under close scrutiny (Robert and Dennis, 2005).

Research to date has examined the effect of group characteristics, task types, and communication media on dependent variables such as performance, satisfaction, and consensus reaching. Each of these studies has examined the effects of these variables independently. The joint effect of these variables has received only limited attention. Generalizing about effects of collaborative technologies has become a challenging research issue (Markus, 2005). In this paper, we study the effects of collaborative systems on the process and outcomes of group decision making. In particular, we investigate how and why computer mediation causes group choices to be different from initial individual choices, if at all.

The purpose of this study is to determine what effect collaborative systems have on group polarization. Previous research suggests that the process of group decision making is dependent on normative influences and persuasive arguments (Siegel et al., 1986). A reduction in either of these two social dynamics may result in a lower degree of polarization for groups working in virtual settings (Sunstein, 2000). We attempt to empirically verify the effects of collaborative systems on group polarization by extending Reder and Conklin's (1987) original model of communicative events.

This study examines group polarization in different communication settings. We focus on three points of reference namely, the composition of the group (homogeneous or heterogeneous), the task (intellective or decision making), and the medium of communication (virtual or FTF) and study their joint and separate impacts on "groupinduced attitude polarization" or group polarization (Isenberg, 1986). The important distinction of this study is our attempt to study the joint and individual effects of these three variables on group polarization as a decision outcome. 


\section{THE RESEARCH MODEL}

In this paper we focus on the model of communicative events to study the group polarization phenomenon (Figure 1). This model incorporates variables of importance to the study of group communication. The model in its original form describes the role of the communication medium as the main direct force influencing the outcomes of group decision making. The role of group and task characteristics, on the other hand according to the model, is that of an indirect effect. This indicates that the effects of group composition and task characteristics differ depending on the medium of communication. The assertions from the model of communicative events related to the impacts of communication medium, group composition and task characteristics are supported by prior efforts. The important distinction of this study is our attempt to jointly and separately study the impacts of these three variables on a decision outcome of importance to group decision making, namely group polarization. Below we discuss the various elements of this model.

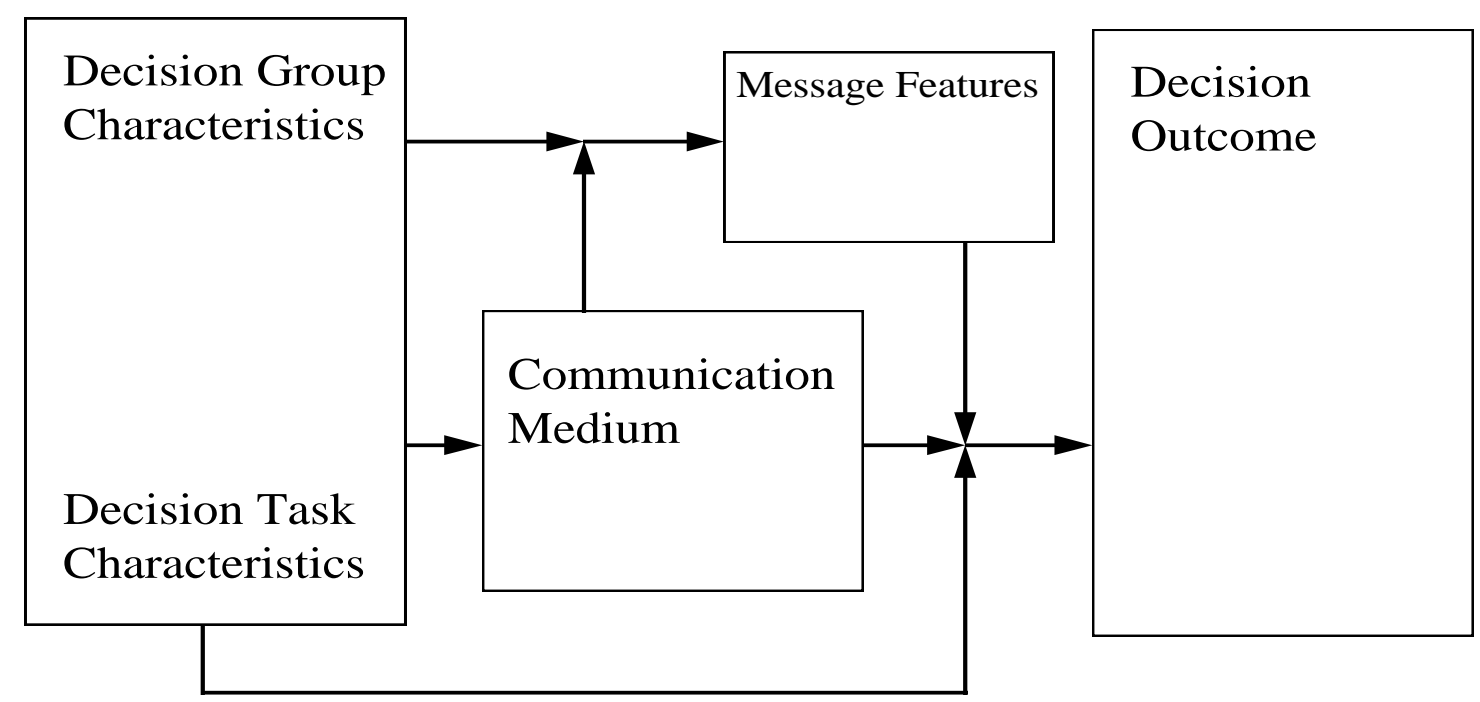

Figure 1: Model of Communicative Events

\section{Communication Medium > Polarization}

Communication media may be classified as rich or lean depending on their ability to carry rich information (Daft and Lengel, 1986; Kahai and Cooper 2003). The richness of a communication medium is a function of four factors: feedback capability, cues, personalization, and language variety. The greater the medium's ability to provide and facilitate timely feedback, the richer it is. If a medium can convey cues such as voice tone and inflection then it is richer than one that does not. The greater the medium's ability to encompass the variety offered by natural language, the richer it is. The more the medium allows a personal focus to convey personal feelings, the higher the medium's richness (Daft and Lengel, 1986).

The above four factors lead to a ranking of media on the richness continuum. Face-to-face interaction ranks highest on richness since it provides immediate feedback, provides verbal as well as visual cues, employs the variety of natural language and is very personal; the telephone ranks high on richness since it provides similar verbal cues as faceto-face interaction, but loses the visual cues; written addressed communication ranks low on richness because visual cues are limited to those on paper, and although natural language is used, audio cues are absent; finally, written un-addressed communication ranks the lowest in richness due to its lack of personalization. This ranking was later extended to include electronic mail. By virtue of electronic mail's written nature it has been ranked low on the richness scale (Daft et al. 
1987). Virtual written communication ranks low on the richness scale by virtue of its written nature and inability to convey social and dynamic cues (El Shinnawy and Markus, 1999).

The two communication media that are considered here are Face to Face meetings and virtual computer based text meetings. The social psychology literature has extensively studied group polarization in the context of face to face meetings (Pruitt, 1971; Lamm and Myers, 1978; Myers, 1982; and Isenberg, 1986). The interest related to the impact of collaborative technology on group polarization is relatively new. The renewed interest in studying polarization using a virtual setting stems from the ability of group technology to effectively introduce anonymity in group settings. The ability of virtual meetings to facilitate anonymous group communication results in deindividuation (Zimbardo, 1969), or allowing social behavior in the absence of social cues. The impact of anonymity has been studied by several researchers (Nunamaker et al., 1987; Jessup et al, 1990; Connolly et al., 1990 and Valacich et al., 1994). Anonymity and its impacts on polarization have been studied by Kiesler et al., (1984) and Siegel et al., (1986). In addition to anonymity, the level of sophistication, degree of control, parallel communication, communication infrastructure and group memory provided by group technology (Nunamaker et al. 1987) can affect both the normative and informational influence processes at work. These in turn may affect the degree and nature of group-induced choice shift. In sum, based on the literature from Media Richness Theory and the literature on the effect of anonymity on the nature of the group's social dynamics and extent of persuasive arguments and social comparison, we predict the following:

H1a: Group polarization will be directly attributable to the communication medium employed.

H1b: Groups will demonstrate a lower degree of polarization in virtual settings when compared with Face-To-Face groups.

\section{Task Characteristics > Polarization}

McGrath's (1984) taxonomy suggests that tasks may be divided into eight categories. This task circumplex has tasks ranging from Planning tasks to Performance/Psycho-motor tasks. For the purposes of this study we focus our attention on "decision-making tasks" and "intellective tasks" as defined by McGrath (1984). Briefly defined, decision-making tasks are open-ended and depend on effective idea generation for their solution. According to Media Richness Theory, these tasks are typically equivocal in nature. Intellective tasks are those for which there is a correct answer based on some logical criteria or facts. These are typically unequivocal tasks.

The importance of task characteristics in group decision making settings is well documented (Raman et al., 1993). Studies have shown that tasks can account for fifty percent of the variance in group performance (Poole et al., 1985). The relationship between task and group polarization was first alluded to by Laughlin (1980) in studying the group-task continuum using task characteristics as the basis. The tasks included in Laughlin's study are intellective tasks, i.e., tasks that have a "correct" final solution, and judgmental tasks (these are similar in nature to the task we label as decision-making tasks in this study), those which do not have a final "correct" solution. Laughlin (1980) found that for intellective tasks, groups polarize toward the "truth" dominated end of the solution, and for judgmental tasks, the groups polarize toward the initial tendency of the majority in the group. A subsequent study by McGuire et al., (1987) extended the results of the Laughlin (1980) study by introducing computer mediation as a way of communication. Their study found results similar to those of Laughlin (1980) when looked at in a face-to-face setting; however, this effect was not as pronounced in computer-mediated settings.

The significance of task characteristics on final decision outcomes is undisputed. The important question that this study addresses is whether task has a direct or an indirect (via the communication medium) relationship to the decision outcome which is defined in terms of group polarization. The Reder and Conklin model (1987) suggests that the impact of task is indirect, while the group polarization literature suggests a more direct link.

Our expectation based on the literature reviewed is that the task choice would have a direct bearing on the decision outcome. Furthermore, that intellective tasks would show a lower polarization effect than the decision 
making tasks, since by their very nature decision making tasks are more open-ended and greater variation is possible in the final solution arrived at by the group. We therefore hypothesize that:

H2a: Group polarization will be directly attributable to the task being addressed.

H2b: Intellective tasks will demonstrate a lower degree of polarization when compared with decision making tasks.

\section{Group Composition > Polarization}

Group composition is one of the basic variables to consider when observing a group decision making process. Researchers in the past have used several approaches to defining group composition. These include individual member characteristics, group size, group history, and group cohesiveness (Dennis et al., 1988). Typically, researchers have used one or more of these characteristics to classify a group as either homogeneous or heterogeneous (Valacich et al., 1993).

The use of group composition to study group decision making has received some attention in the management literature (Valacich et al., 1993; Nunamaker et al., 1989), but has not received the same degree of attention in the group polarization literature. Using the prior findings from Valacich et al., 1993 and Nunamaker et al., 1989, we assert that group composition should have an impact on group polarization and attempt to document the degree and extent of its impact. The study addresses the following hypotheses in relation to group composition:

H3a: Group polarization will be directly attributable to the composition of the group.

H3b: Homogeneous groups will demonstrate a lower degree of polarization when compared with heterogeneous groups

\section{Task*Medium > Polarization}

Daft et al. (1987) argue that for effective communication there must be a fit between the task and the richness of information that can be transmitted on a communication medium. The fundamental claim of Media Richness Theory is that, for effective communication, individuals should match media to communication tasks. Rich, oral media such as face-to-face interaction, enable negotiation, clarification, explanation and exchange of subjective views. On the other hand, media of low richness, such as written and computer-mediated media, while effective for processing standard, nonambiguous information, are not appropriate for resolving equivocal issues (Sheer and Chen, 2004).

Equivocality refers to ambiguity (Daft, Lengel and Trevino 1987) and usually is associated with multiple and conflicting interpretations of situations. In situations of equivocality, it is not evident what questions need to be asked and, if questions are asked, no clear answers are likely to be available (March 1974). According to Daft, Lengel and Trevino (1987), equivocality stems from situations where individuals' frames of reference differ and negotiation is necessary to reach an understanding and a solution. To resolve equivocality individuals need to negotiate, explain, clarify and exchange existing subjective opinions in order to define the problem and give meaning to an ambiguous situation.

Communication media need to promote the ability to clarify, negotiate, and explain in order to reduce equivocality. The issue in the resolution of equivocality is the ability of the communication medium to process "rich" information (Daft and Lengel, 1986). Communication media differ in their capacity to process rich information. Media Richness theory suggests that communication media can be ranked on a one-dimensional continuum, labeled the richness of the medium based on the medium's ability to handle equivocality.

McGrath and Hollingshead (1993) applied the notion of task-communication media fit developed by Daft et al., 1986 to group technology. In a study by Hollingshead et al. (1993), the researchers document via a longitudinal study the relationship between task characteristics and communication technology. An important finding of this 
study was that task type moderates the effect of communication medium. The task classification used here follows McGrath's circumplex categorization of group tasks. Decision Making tasks deal with tasks that are more open-ended and focus on generating ideas. These are equivocal tasks that have no correct solution. Individuals bring forth their different backgrounds, opinions, agendas, and motives in attempt to reach consensus. Typically, consensus in Decision Making tasks is more difficult. Intellective tasks, on the other hand, are typically tasks focused on solving problems, where correct answers for these problems exist, i.e. non-equivocal tasks (Daft et al. 1987). Since a correct answer exists and is possible, little negotiation is necessary to reach consensus.

The above two research streams suggest that the type of task performed moderates the effect of the communication medium on group polarization. The type of communication medium in use either permits or filters out various social and dynamic cues that may influence the nature and extent of group polarization. In addition, the nature of the task will have a mediating effect on this relationship.

The expectation is that, in general, individuals will polarize less in virtual settings than in Face-to-Face settings. However, the nature and extent of this polarization will also depend on which tasks they are performing. As discussed earlier, for intellective tasks the nature and degree of polarization will not be as pronounced as for decision making task. As a result, we predict that polarization will be most pronounced in face-to-face situations when individuals are dealing with Decision Making tasks that require deciding issues with no correct answers. On the other hand, polarization will be least pronounced in virtual situations where individuals are dealing with simple intellective tasks. The other two situations virtual/decision making tasks and FTF/intellective tasks will lie between these two extremes.

H4: The effect of the communication medium on group polarization will be mediated by the type of task performed.

H4a: In Decision making tasks, FTF groups will experience the highest degree of polarization.

H4b: In Intellective tasks, virtual groups will experience the lowest degree of polarization.

\section{Group Composition * Medium > Polarization}

The composition of the group will have a moderating effect on the degree of polarization through an interaction with the communication medium. The nature of the group will be important in face-to-face situations where there is some social comparison and where group dynamics play an important role in the outcome and the group process. Since virtual situations filter out the effects of the degree of heterogeneity in the group, we predict the following:

H5: The effect of the communication medium on group polarization will be mediated by the composition of the group.

H5a: Heterogeneous, Face-To-Face groups will experience the highest level of group polarization.

H5b: Homogeneous virtual groups will experience the lowest level of group polarization

\section{Proposed Research Model}

Figure 2 summarizes the proposed research model. The proposed model focuses on studying group polarization. The original Reder and Conklin (1987) model was modified to include a direct effect of group composition and task characteristics on our outcome variable of polarization. In addition, the tasks we focus on are based on both McGrath's task circumplex and Daft and Lengel's notion of task-media fit. Moreover, the characteristics of the group build on the notion of homogeneous and heterogeneous group composition and their effect on group process and outcome. 


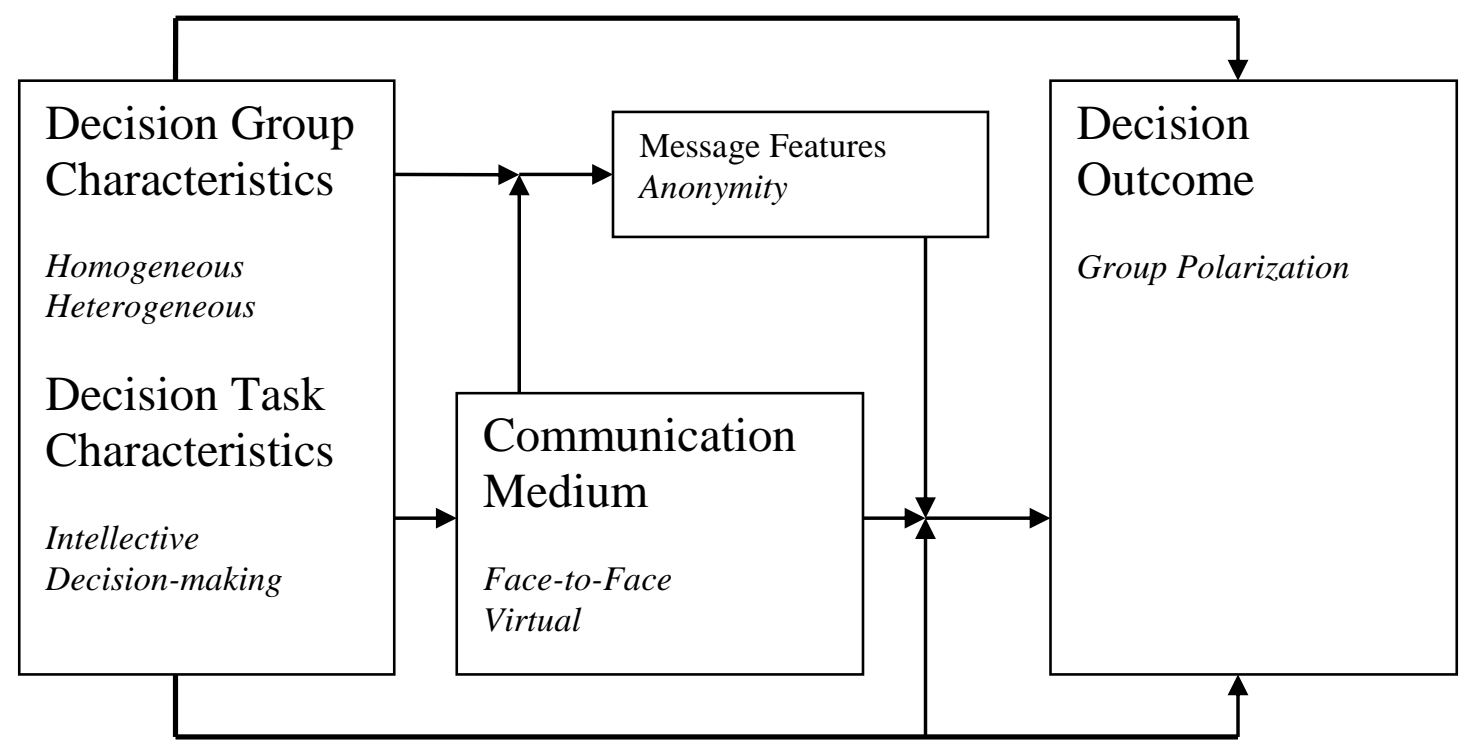

Figure 2: Proposed Research Model

\section{RESEARCH DESIGN AND METHODS}

A laboratory experiment was conducted to test the research model described in Section 2. Participation in the study was voluntary and involved a three hour evening session for each group.

\section{Subjects And Tasks}

The subjects for this experiment were graduate and undergraduate students at a large southern university. A total of 168 students participated in this study. The graduate students (106) were all enrolled in the MBA program. The undergraduate students (62) were all graduating seniors.

The subjects were given two tasks (see Appendix A and B) that were labeled "The Pentium Problem" and "Business Strategy" respectively. The subjects were also provided two articles, from Business Week (Hof, 1995) and Fortune Magazine (Kirkpatrick, 1994). These articles provided background information on Andrew Grove, the CEO of Intel, and the business direction Intel is taking. The articles also described the current Pentium situation. The subjects were asked to attempt these two tasks, individually, the day before their participation in the experiment. The tasks were labeled as intellective or decision-making from the McGrath (1984) task classification. The Pentium problem, given that the situation was evolving in the press and had a correct solution was labeled as the "intellective task." The business strategy task was more open ended and depended on effective idea generation and negotiation for its solution. This was labeled "decision-making task."

In addition to completing the task before coming to the experiment, the subjects were required to complete the "Strengths Deployment Inventory ${ }^{\circledR}$ ". The SDI questionnaire is a pre-tested, validated, and commercially available instrument. This questionnaire helps individuals assess their strengths in relating to others in group situations. Based on individual responses to this questionnaire, they are classified as either "red," "green," or "blue." The "red" individuals are typically described as assertive and directing, the "green" individuals are classified as analytic-autonomizing and the "blue" individuals are labeled as altruistic-nurturing. Using the individual 
classification of red, green, or blue, we label our groups as either homogeneous or heterogenous. Homogeneous groups are those with at least one individual from each of three (red, green, or blue) classifications represented. Heterogeneous groups are those without representation from each of the three classifications.

\section{Procedure}

The experiment was conducted as part of a three hour seminar titled "Managing Interpersonal Communication and Group Effectiveness." The entire experiment was conducted in five sessions over a four week period. Six groups participated in each of the first two sessions and the following three sessions had seven groups each.

The seminar was divided into three parts. The first 30 minutes were spent on a formal presentation about interpersonal communication. For the following two hours, the groups attempted the task in either a face to face or a virtual setting. Each group was given approximately one hour in each of the two settings. The final thirty minutes were spent discussing the experiences of the participants in each of the two communication media, and getting some informal feedback on how they felt their personality type (based on the SDI questionnaire) worked out for each of the two settings.

As the groups broke to attempt the task, they were given minimal instructions, and were asked to come to consensus on a solution for the two problems. For the face-to-face meetings, breakout rooms were setup and each of these sessions was video recorded. The virtual groups attempted their tasks using The Meeting Room ${ }^{\circledR}$ software in a computer lab. The virtual session comprised of the Brainstorming and Voting exercises. The discussion in the virtual session was captured via transcripts of the entire session.

\section{Analysis}

The experiment was designed as a $2 \times 2 \times 2$ (Communication medium $\times$ Task $\times$ Group Composition) factorial. The dependent variable was "polarization." Polarization was measured by the difference between the consensus arrived at in a group decision and the decision that the individual reported prior to the start of the seminar. The dependent variable polarization was therefore measured with two sets of figures. The first set was obtained by taking the difference between the Individual decision and the FTF consensus decision. The second set of figures on polarization was obtained by taking the difference between Individual decisions and virtual- based consensus.

The independent variables were: communication medium (FTF or virtual); task characteristics (decision making or intellective); and, group composition (homogeneous or heterogeneous). The distinction between the two types of media was that one medium was Face-To-Face and the other was virtual. For task characteristics, we defined the Business Strategy task as the decision-making or equivocal task and the Pentium problem as the intellective or unequivocal task. The group composition as described in the previous section was based on the SDI questionnaire, and the groups were labeled as either homogeneous or heterogeneous.

In conducting the experiment we controlled for certain factors found to be significantly related to decision outcomes in previous studies (Fjermestad et al. 1993): instructions to the subjects; time taken to complete the task; group size; and, the order in which the medium was used. All the instructions to the subjects followed a well defined script. A one hour time allocation was made to attempt each task regardless of the medium. The groups were all composed of six subjects. During the actual conducting of the experiment however, due to the absence of some of the subjects, certain groups were comprised of 5 individuals. As for the order in which the medium was used, half the groups did the virtual session first, followed by the FTF session, the other half attempted the task starting with the FTF session and followed by the virtual session.

Using a factorial Anova, and keeping with the hypotheses discussed in Section 2, we looked for three main effects (hypotheses 1a, 2a, and 3a) and two interaction effects (hypotheses 4, and 5). Additionally, we conducted ttests to document the direction of the polarization for each of the three independent variables (hypothesis $1 \mathrm{~b}, 2 \mathrm{~b}$, and $3 b$ ) and for the interaction effects (hypothesis $4 a, 4 b, 5 a$ and 5b). 


\section{RESULTS}

Analysis of Variance with planned comparisons was used to test the hypotheses put forth in the previous sections. Planned contrasts were used to tests the a priori comparisons specified in hypotheses $4 \mathrm{a}, 4 \mathrm{~b}, 5 \mathrm{a}$, and $5 \mathrm{~b}$. The design has 8 cells. This provides 7 degrees of freedom to test 3 main effects (medium, group and task) and 4 interactions. TABLE 1 presents the significance of the overall model fit $(\mathrm{F}=4.21, p<0.0008)$. Also, the results of the Analysis of Variance and planned comparisons are presented in TABLE 2. In addition, the polarization means for the significant treatments are presented in TABLE 3. The level of statistical significance was set at $\square \square<0.05$.

Table 1: Overall Model Fit

\begin{tabular}{|l|c|c|c|c|c|c|}
\hline \multicolumn{1}{|c|}{ Source } & DF & $\begin{array}{c}\text { Sum Of } \\
\text { Squares }\end{array}$ & Mean Square & F Value & Pr > F & Signficant? \\
\hline Model & 7 & 343.12 & 49.02 & 4.21 & 0.0008 & YES \\
\hline Error & 57 & 663.36 & 11.64 & & & \\
\hline Corrected Total & 64 & 1006.48 & & & & \\
\hline
\end{tabular}

Table 2: Results Of Anova's And Planned Contrasts

\begin{tabular}{|l|c|c|c|c|c|c|}
\hline \multicolumn{1}{|c|}{ Source } & DF & $\begin{array}{c}\text { Sum Of } \\
\text { Squares }\end{array}$ & Mean Square & F Value & Pr > F & Significant? \\
\hline Medium & 1 & 60.66 & 60.66 & 5.21 & 0.026 & YES \\
\hline Group Comp & 1 & 0.344 & 0.344 & 0.03 & 0.864 & NO \\
\hline Task & 1 & 110.19 & 110.19 & 9.47 & 0.003 & YES \\
\hline Med*Grpcmp & 1 & 52.29 & 52.29 & 4.49 & 0.038 & YES \\
\hline Med*Task & 1 & 90.17 & 90.17 & 7.75 & 0.007 & YES \\
\hline Grpcmp*Task & 1 & 14.31 & 14.31 & 1.23 & 0.272 & NO \\
\hline
\end{tabular}

\section{Main Effects}

As we can see from TABLE 2, there was a significant main effect for medium $(\mathrm{F}=5.21, p<.0262)$. Hypothesis 1 was supported; the communication medium has an effect on the degree of polarization. In addition, Hypothesis $1 \mathrm{~b}$ was also supported (see TABLE 3). This hypothesis predicted which medium will witness greater polarization. Using the LSD procedure, as predicted, the degree to which groups polarized in virtual settings was significantly lower than in face-to-face settings (means $=0.4167,-1.5156$ ). Also of interest is another unexpected finding that polarization in the two media follows different directions. In virtual settings groups polarize in one direction whereas in FTF settings groups polarize in the other direction using the same set of tasks.

Table 3: Means For Significant Treatments

\begin{tabular}{|c|c|c|}
\hline Treatment & Means & Direction of Shift \\
\hline Face-To-Face & -1.5156 & Risky \\
\hline Virtual & 0.4167 & Cautious \\
\hline Decision Making & -1.7422 & Risky \\
\hline Intellective & 0.6364 & Cautious \\
\hline
\end{tabular}

Using LSD with: $\square=0.05, \mathrm{df}=57, \mathrm{MSE}=11.638$

Hypothesis 2a postulated that the nature of the task will have a main effect on group polarization. This hypothesis was supported (TABLE 2: $\mathrm{F}=9.47, p<0.0032$ ). Also, as predicted in Hypothesis $2 \mathrm{~b}$, groups working on intellective tasks polarized less than those working on more equivocal, decision making tasks. (TABLE 3: means= 
0.6364, -1.7422). Also of interest is the direction of shift. Decision Making tasks shifted in the risky direction whereas Intellective tasks had a tendency to shift in the direction of caution.

There was no significant main effect for Group Composition (TABLE 2). Group composition had no effect on the extent to which individuals polarized. Hypotheses $3 \mathrm{a}$ and $3 \mathrm{~b}$ were not supported.

\section{Interactions}

Hypothesis 4 was supported (TABLE 2: $\mathrm{F}=7.75, p<0.0073$ ). The effect of communication medium on group polarization will be mediated by the type of task performed. In addition, Bonferroni tests of differences between means for the 4 treatment effects were conducted. The results (TABLE $4 \& 5$ ) reveal that at the 0.05 level, treatment 1(Face-To-Face, Decision Making task) is significantly different from the 3 other treatments. The Bonferroni test for Hypothesis 4a reveals that FTF groups working on equivocal, decision making tasks experience the highest degree of polarization (see also Figure 3). Hypothesis $4 \mathrm{~b}$ was not, however, supported. The Bonferroni test did not show that virtual groups working on Intellective tasks experience the lowest degree of polarization.

Table 4: Treatment Effects For Hypotheses 4a And 4b

\begin{tabular}{|c|c|c|c|c|c|c|}
\hline Contrast & DF & Contrast SS & Mean Square & F Value & Pr > F & Significant? \\
\hline H4a & 1 & 258.31 & 258.31 & 21.10 & 0.0001 & YES \\
\hline H4b & 1 & 33.64 & 33.64 & 2.75 & 0.1025 & NO \\
\hline
\end{tabular}

Table 5: Means For Interaction Effects Task X Medium

\begin{tabular}{|c|c|c|c|}
\hline Level of Medium & Level of Task & Mean & Standard Deviation \\
\hline Face-to-Face & Decision Making & -4.34 & 4.16 \\
\hline Face-to-Face & Intellective & 0.68 & 1.47 \\
\hline Virtual & Decision Making & 0.28 & 4.22 \\
\hline Virtual & Intellective & 0.58 & 3.61 \\
\hline
\end{tabular}

Using LSD; a=0.05, df=57, MSE=11.64

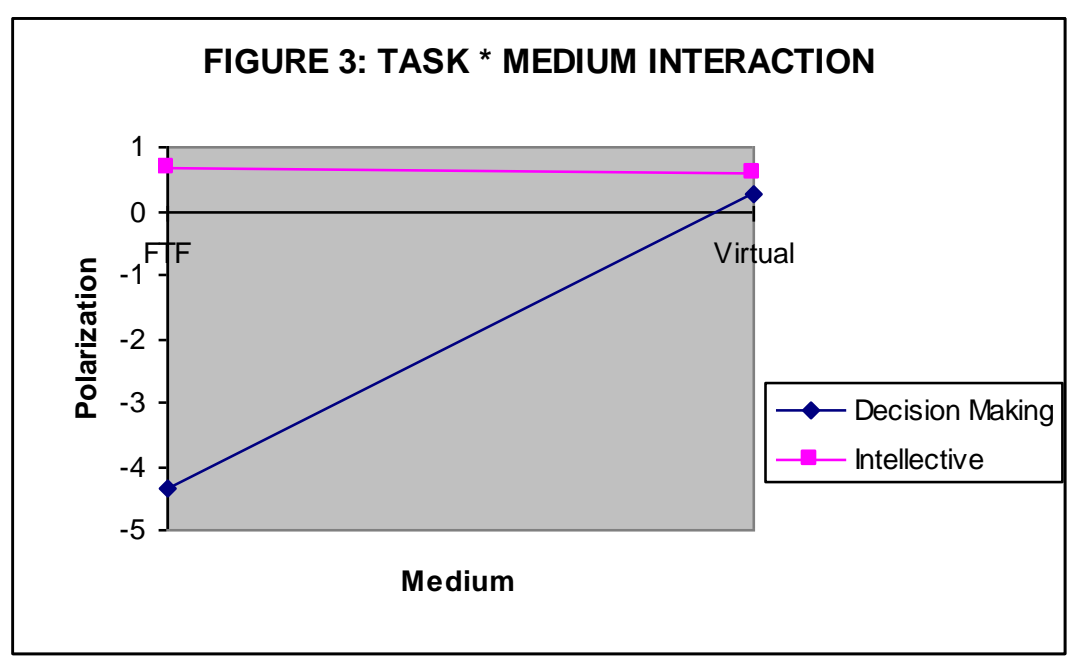


Interestingly, while there is no main effect for group composition on the dependent variable of polarization, there is a significant interaction between Group Composition and Medium (TABLE 2: $\mathrm{F}=4.49, p<0.0384$ ). The effect of communication medium on group polarization is mediated by the composition of the group. Hypothesis 5 was thus supported.

Table 6: Treatment Effects For Hypotheses 5a And 5b

\begin{tabular}{|c|c|c|c|c|c|c|}
\hline Contrast & DF & Contrast SS & Mean Square & F Value & Pr > F & Significant? \\
\hline H5a & 1 & 0.000 & 0.000 & 0.00 & 0.9992 & NO \\
\hline H5b & 1 & 76.26 & 78.26 & 5.27 & 0.1025 & NO \\
\hline
\end{tabular}

Table 7: Means For Interaction Effects Grpcomp X Medium

\begin{tabular}{|c|c|c|c|}
\hline Level Of Medium & Level Of Group Comp & Mean & Standard Deviation \\
\hline Face-to-Face & Homogeneous & -2.65 & 4.23 \\
\hline Face-to-Face & Heterogeneous & -0.515 & 3.28 \\
\hline Virtual & Homogeneous & 1.464 & 3.47 \\
\hline Virtual & Heterogeneous & -0.355 & 4.10 \\
\hline
\end{tabular}

Both hypotheses 5a and 5b are not supported. Heterogeneous, Face-To-Face groups did not experience the highest degree of polarization (H5a). Also, homogeneous, Virtual groups did not experience the lowest degree of polarization $(\mathrm{H} 5 \mathrm{~b})$. In general, the only group that showed any polarization are homogeneous groups working in Face-to-Face situations. Bonferroni tests of differences between means for the 4 treatment effects demonstrate that at at the 0.05 level of significance only two treatments are significantly different from one another: homogeneous groups working in a Face-To-Face setting and homogeneous groups working in a virtual setting (see FIGURE 4).

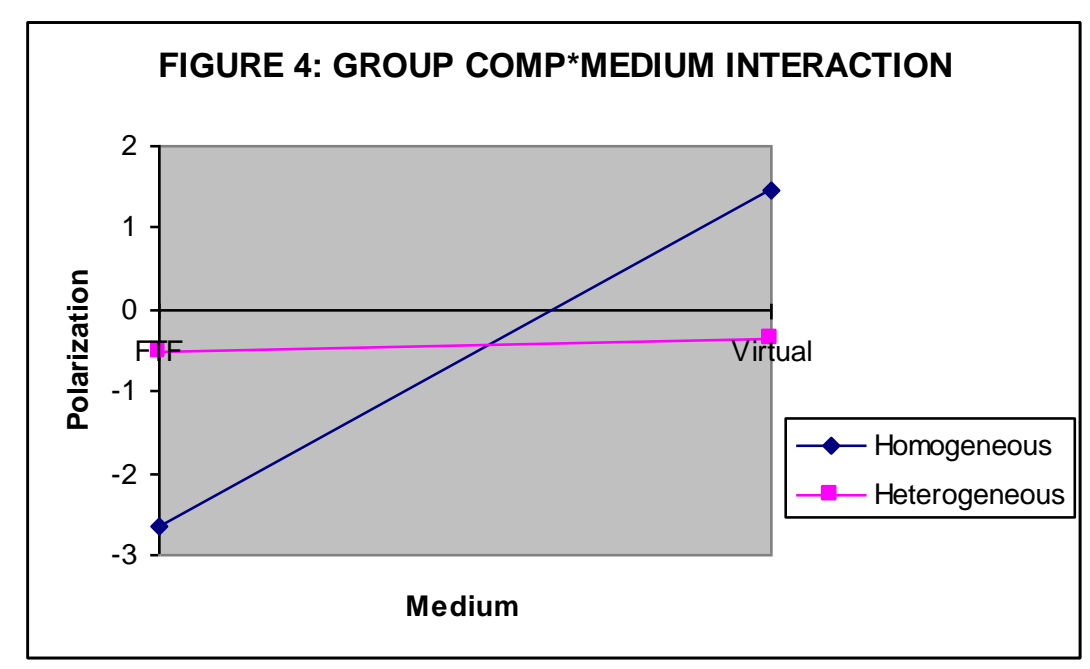

\section{DISCUSSION AND CONCLUSIONS}

The purpose of this study was to understand why group polarization occurs and the mechanisms that underlie this phenomenon. A second goal was to evaluate the impact of virtual settings on the phenomenon of group polarization. We used the model of communicative events to initiate this effort as this model addresses the various facets that these basic questions suggest. The model that we worked with was an extension of the original Reder and Conklin (1987) model. We proposed a direct link from "decision task characteristics," and the "decision group 
characteristics" to the final decision outcome in a group process. The final decision outcome that we focus on is group polarization measured by the change that the group mediation caused on an individual's initial decision. Our extensions to the model were based on prior works related to Media Richness Theory and Social Comparison and Persuasive Arguments Theories that have been extensively documented in the group polarization literature (ElShinnawy and Vinze, 1998).

The results from this study partially confirmed our proposed research model. First, the results confirmed the direct impact of communication medium (FTF and virtual) on the final decision outcome. Our extension to the model however had mixed results. The data analysis demonstrated that task characteristics have a direct bearing on polarization, however the composition of the group does not have a significant impact on polarization.

To further scrutinize the impact of the three independent variables considered: medium; task characteristics; and group composition, we focus on the direction of polarization, i.e., does polarization occur in the direction of risk or does it move toward caution. Research efforts on group suggest that decision shifts may be in the direction of risk or caution. The findings in this study suggest that the type of medium has an impact on the direction of the shift. The data suggests that for face-to-face meetings the shift was in the direction of risk, and for virtual meetings, with anonymity as a key feature, polarization occurred in the direction of caution.

With regards to the task characteristics, the results indicate that for equivocal or decision-making tasks, the polarization is higher when compared to the unequivocal or intellective tasks. This finding supports previous work that suggests that task will account for much of the variance in group performance. Both the task circumplex (McGrath, 1984) and Media Richness Theory contend that individuals tend to have less trouble reaching consensus in simple intellective tasks than in equivocal decision making tasks. Our research supports this previous body of work.

In addition to the main effects, our analysis also confirmed the interaction between task characteristics and medium and the interaction of group composition and medium. We view these interactions from the perspective of the direction of polarization as well. For the task*medium interaction, we find that for unequivocal tasks, the medium has little impact on polarization. For equivocal tasks however, the medium has a dramatic effect, and that for these types of tasks, Face-To-Face meetings create more risk oriented decisions while virtual groups tend more towards caution. This finding provides strong support for Media Richness Theory. It suggests that there is a significant difference in the decision making outcome, polarization, for equivocal decision making tasks. The findings are fascinating from a number of perspectives. First, they reveal that as documented in the literature on group polarization, in Face-to-Face situations individuals tend to polarize. However, this finding also suggests that in keeping with Media Richness Theory, both the nature of the task and the medium of communication are important determinants of the decision making outcome. Since virtuality removes many of the social cues associated with FaceFace communication, individuals have less reason to appear as risk takers and have less reason to follow their superiors or highly regarded others. As such, individuals tend to hold their ground and not to polarize. Moreover, the direction of polarization is also noteworthy. The social psychology literature and specifically the work on group polarization suggests that one of the important reasons for polarization is that risk is a valued trait. If we view our results in Figure 3 we will notice that for the equivocal tasks, individuals are very risk oriented in the Face-To-Face situation and cautious in the virtual situation. This provides support for the literature on polarization in face-to-face situations and confirms our prediction that features of the technology that filter out various social cues will allow individuals to polarize less and to be less risky.

The group composition*medium interaction is a little more difficult to interpret. This is primarily because the impact of group composition by itself was not significant. The plot of this interaction however suggests that the medium has little effect on heterogeneous groups. However, for homogeneous groups, there is a significant difference in the direction of shift. In Face-to-Face situations groups tend to experience a risky shift while in virtual situations groups experience a cautious shift. Once again, it seems that the medium is having a large role in explaining the degree and the direction of shift for homogeneous groups.

The findings from this study should be interesting to researchers studying group polarization and group dynamics, as well as those interested in Media Richness Theory. In particular, we feel that these finding further our 
understanding of why group polarization occurs. This study also provides insights on the impact that medium, task characteristics and group composition have on the polarization phenomenon and the interrelations among them.

The results of this study provide support for the revised version of Reder and Conklin's (1987) model with the exception of the direct link between the composition of the group and the degree of polarization. In addition, our results suggest that, while group polarization is a phenomenon that has been documented by researchers for the last 30 years, the medium of communication is a major factor in determining the nature, extent, and direction of group polarization. Virtuality eliminates some of the group dynamics allowing individuals to shift less and confirm to their original individual opinions. If individuals change their prior decisions at all, it is usually in the direction of caution and to a very small degree.

These results are fascinating to researchers and practitioners alike. They shed light on Theories of Social Psychology such as Persuasive Arguments Theory and Social Comparison Theory and they provide further empirical evidence for communication theories such as Media Richness Theory. For practitioners these results have implications for group decision making activities where the substance of the group discussion rather than social dynamics should determine the outcome of the group decision outcome. In today's virtual organization where much of the work is conducted across time and space, these results are particularly significant.

\section{LIST OF REFERENCES}

1. Connolly, T., Jessup, L. M., and Valacich, J. S., Effects of Anonymity and Evaluative Tone on Idea Generation in Computer-mediated Groups, Management Science, 1990, 36(6), pp. 689-703.

2. Daft, R. L. and Lengel, R. J. Organizational Information Requirements, Media Richness And Structural Design. Management Science, 32, 1986, Pp. 554-571.

3. Daft, R. L., Lengel, R. H., and Trevino, L.K. Message Equivocality, Media Selection, And Manager Performance: Implications For Information Support Systems. MIS Quarterly, 11, 1987, Pp. 355-366.

4. Dennis, A. R., George, J. F., Jessup, L. M., Nunamaker, J. F., and Vogel, D. R., Information Technology to Support Electronic Meetings, MIS Quarterly, 1988, 12(4), pp. 591-624.

5. El-Shinnawy, Maha and Markus, M. Acceptance of Communication Media in Organizations: Richness or Features? IEEE Transactions on Professional Communication, March 1999.

6. El-Shinnawy, Maha and Vinze, A. (1998) Polarization and persuasive argumentation: A study of decision making in group settings. MIS Quarterly. Minneapolis: Jun 1998. Vol. 22, Issue 2; p. 165.

7. Fjermestad, J., Starr, R. H., and Turoff, M., An Integrated Framework for the Study of Group Decision Support Systems, Proceedings of the Twenty Sixth Annual Hawaii International Conference on System Sciences, Vol. IV, 1993, pp. 179-188.

8. Hollingshead, A. B., McGrath, J. E., and O'Connor, K. M. Group Task Performance and Communication Technology, Small Group Research, Vol. 24, 3, August 1993.

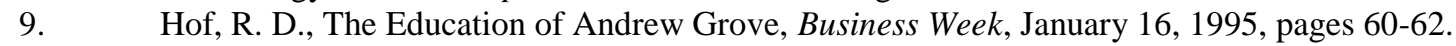

10. Isenberg, D. J., Group Polarization: A Critical Review and Meta Analysis, Journal of Personality and Social Psychology, Vol. 50, No. 6, 1986, pp. 1141-1151.

11. Jessup, L. M., Connolly, T., and Galegher, J., The Effects of Anonymity on GSS Group Process with an IdeaGenerating Task, MIS Quarterly, 14(3), 1990, pp. 313-321.

12. Kahai, S. and Cooper, R. (2003) Exploring the core concepts of Media Richness Theory: The impact of cue multiplicity and feedback immediacy on decision quality. Journal of Management Information Systems. Armonk: Vol. 20, Issue. 1; p. 263

13. Kiesler, S., Siegel, J., and McGuire, T. W., Social Psychological Aspects of Computer-Mediated Communication, American Psychologist, 39(10), 1984, pp. 1123-1134.

14. Kirkpatrick, D., Intel Goes For Broke, Fortune, May 16, 1994, Pages 62-68.

15. Kock, N. (2005). What is E-Collaboration. International Journal of E-Collaboration. Vol. 1, issue 1.

16. Lamm, H. and Myers D. G., Group-Induced Polarization of Attitudes and Behavior, Advances in Experimental Social Psychology, Vol. 11, Academic Press, New York, 1978, pp. 145-195.

17. Laughlin, P. R. Social Combination Processes of Cooperative Problem Solving groups on verbal intellective tasks. In M. Fishbein (Ed.), Progress in Social Psychology (pp. 127-155), 1980. 
18. March, J. G. (1974). Bounded Rationality, Ambiguity, and the Engineering of Choice. Bell Journal of Economics, 9, 338-353.

19. Markus, M. (2005). Technology-shaping Effects of E-Collaboration Technologies: Bugs and Features. International Journal of E-Collaboration. Vol. 1, issue 1.

20. McGuire, T. W., Kersler, S., and Siegel, J., Group and Computer-Mediated Discussion Effects in Risk Decision Making, Journal of Personality and Social Psychology, 52(5), 1987, pp. 917-930.

21. McGrath, J. E. Groups: Interaction and Performance. Englewood Cliffs, NJ: Prentice-Hall, 1984.

22. McGrath, J. E. and Hollingshead, A. B. Putting the Group Back in Group Support Systems: Some Theoretical Issues about Dynamic Processes in Groups with Technological Enhancements. In L.M. Jessup and J. Valacich (Eds) Group Support Systems: New Perspectives. New York, 1993.

23. Myers, D. G., Polarizing Effects of Social Interaction. In H. Brandstatter, J. H. Davis, and G. StocherKreichgauer (Eds.), Contemporary Problems in Group Decision Making. Academic Press, New York, 1982, pp. $125-161$.

24. Nunamaker, J. F., Jr., Applegate, L., and Konsynski, B. Facilitating Group Creativity: Experience with a Group Decision Support System, Journal of Management Information Systems, 3(3), 1987, pp. 5-19.

25. Nunamaker, J. F., Vogel, D. R., Heminger, A., Martz, B., Grohowski, R., and McGoff, C. Experiences at IBM with Group Support Systems: A Field Study, Decision support Systems, 1989.

26. Poole, M. S., Siebold, D. R., and McPhee, R. D. Group Decision Making as Structuration Process, Quarterly Journal of Speech, 71, 1985, pp.74-102.

27. Pruitt, D. G., Choice Shifts in Group Discussion: An Introductory Review, Journal of Personality and Social Psychology, 20(3), 1971a, pp. 339-360.

28. Pruitt, D. G., Conclusions: Toward an understanding of choice shifts in group discussion, Journal of Personality and Social Psychology, 20(3), 1971b, pp. 495-510.

29. Raman, K. S., Tan, B. C., and Wei, K. K. An Empirical Study of Task Type and Communication medium in GDSS, Proceedings of the Twenty-Sixth Hawaii International Conference on System Sciences, Vol. IV, 1993.

30. Reder, S. and Conklin, N. F. Selection and Effects of Channels in Distributed Communication and DecisionMaking Tasks: A Theoretical Review and a Proposed Research Paradigm, Presented at the 37th Annual Conference of the International Communication Association, Montreal, Canada, 1987.

31. Robert, L. and Dennis, A. (2005) Paradox of Richness: A Cognitive Model of Media Choice IEEE Transactions on Professional Communication. New York: Vol. 48, Issue. 1; p. 10

32. Sheer, V. and Chen, L. (2004) Improving Media Richness Theory: A Study of Interaction Goals, Message Valence, and Task Complexity. Management Communication Quarterly.

33. Sunstein, C. R. (2000). Deliberative trouble? Why groups go to extremes The Yale Law Journal New Haven: Oct. Vol. 110, Issue. 1; p. 71.

34. Siegel, J., Dubrovsky, V., Kiesler, S., and McGuire, T.W., Group Processes in Computer-Mediated Communication, Organizational Behavior and Human Decision Processes, 37, 1986.

35. Valacich, J. S., Dennis, A. R., and Connolly T. Idea Generation in Computer-based Groups: A New Ending to an Old Story, Organization Behavior and Human Decision Processes, 1993.

36. Valacich, J. S., Dennis, A. R., and Connolly, T. Idea Generation in Computer-based Groups: A New Ending to an Old Story, Organization Behavior and Human Decision Processes, 1994, 57, pp. 448-467.

37. Zimbardo, P. G., The Human Choice: Individuation, Reason and Order versus De-individuation, Impulse, and Chaos, in W. J. Arnold and D. Levine (Eds), Nebraska Symposium on Motivation, University of Nebraska Press, Lincoln, 1969. 


\section{APPENDIX A}

\section{Decision Making Task - Business Strategy}

Intel has traditionally pumped megabucks into product development and factories and thus has established itself as the hardware hegemon of the PC revolution, much as Bill Gates has made Microsoft the software champ. Recent developments in the consumer market for PCs has Intel convinced that before long, consumers and not corporate customers will keep Intel's riches flowing. As a result, Intel needs to evaluate its business strategy.

As a consultant advising Andy Grove on this matter what issues do you feel should be considered as Intel plots its future direction?

What issues would you consider critical?

\section{Characterize your decision on the following scale:}

\begin{tabular}{|l|l|}
\hline 1 & Pursue your interests strictly as an engineering company \\
2 & Direct most resources to improving process efficiency \\
3 & Direct most resources to product enhancement \\
4 & Balanced mix of improved process and introducing new products \\
5 & Direct most resources to developing new products to meet identified customer needs \\
6 & Direct most resources to addressing and understanding customer needs without changing the product or \\
& the process \\
7 & Pursue your interests strictly as a consumer-oriented company \\
\hline
\end{tabular}

\section{APPENDIX B}

\section{Intellective Task - Pentium}

When word about a flaw in the Intel's new Pentium chip began circulating before thanksgiving 1994 it was viewed by Intel, initially, as an inconvenience. Having kept the defect a secret for months, Intel was caught unprepared in December by IBM's decision to halt shipments of its machine containing the Pentium chip.

If you were on the board of directors of Intel advising the CEO, Andrew Grove, what issues would you advise Mr. Grove to consider in developing Intel's policy to deal with the Pentium case?

What issues would you consider critical?

\section{Characterize your decision on the following scale:}

\begin{tabular}{|l|l|}
\hline 1 & Complete product recall, replacement of computer plus restitution \\
2 & Complete computer replacement, no restitution \\
3 & Replace pentium chip only \\
4 & Test all chips at Intel site. Replace chip if flawed. Otherwise return chip \\
5 & Agree that problem MAY exist in a few cases. If justified, send a new pentium chip \\
6 & Agree that problem MAY exist in a few cases, but indicate that it is noncritical and thus unimportant \\
7 & Complete denial of the existence of the problem \\
\hline
\end{tabular}

